\title{
Stepwise synthesis of a stable diphosphasilirane and its unexpected dimerization $\uparrow$
}

Cite this: Chem. Commun., 2014

50, 7709

\author{
Kirsten Reuter and Carsten von Hänisch*
}

Received 4th April 2014

Accepted 28th May 2014

DOI: $10.1039 / \mathrm{c} 4 \mathrm{cc} 02489 \mathrm{c}$

www.rsc.org/chemcomm

The synthesis of the thermally stable bicyclic diphosphasilirane $\mathrm{O}\left(\mathrm{SiiPr}_{2} \mathrm{P}_{2} \mathrm{SiiPr}_{2}\right.$ (4) was achieved via oxidation of the alkaline earth metal substituted cyclic diphosphanide 3 with 1,2-dibromoethane. Nonetheless, during extended storage at low temperature, impurity induced rearrangement in favour of the dimeric species $\left[\mathrm{O}\left(\mathrm{SiiPr}_{2} \mathrm{P}_{2} \mathrm{SiiPr}_{2}\right]_{2}(5)\right.$ is observed.

The stability of three-membered heterocycles strongly depends on the skeleton atoms and their substituents. For example the ring strain drops in the series from cyclotrisilane to the heterocyclic compound $\mathrm{Si}_{2} \mathrm{PH}_{5}{ }^{1}$ and finally to the almost unstrained cyclotriphosphine. ${ }^{2}$ Also bulky substituents give rise to increased stability of small ring systems. ${ }^{3,4}$ This can best be illustrated by the ring compound $(t \mathrm{BuP})_{2} \mathrm{SiMe}_{2}$, synthesized by Baudler et al., which easily decomposes in favour of larger ring systems, while in the case of the analogous phenyl substituted $(t \mathrm{BuP})_{2} \mathrm{SiPh}_{2}$ no by-products occur. ${ }^{5}$

In prior work, alkaline earth metal derivatives of primary and secondary phosphides turned out to be valuable starting materials for oxidative phosphorus-phosphorus coupling. ${ }^{6}$ With the aim to synthesize a stable diphosphasilirane, we tried to integrate the $\mathrm{P}_{2}$-unit into a robust five-membered ring. Therefore, the cyclic compound 1 seems to be a promising starting material. The synthesis of $\mathbf{1}$ is accomplished through metalation of $\mathrm{O}\left(\mathrm{SiiPr}_{2} \mathrm{PH}_{2}\right)_{2}$ by $n \mathrm{BuLi}$ and subsequent reaction with $\mathrm{SiiPr}_{2} \mathrm{Cl}_{2}$ (Scheme 1), which yields $75.3 \%$ of a highly-viscous, colourless oil.

At $-25^{\circ} \mathrm{C}$, compound $\mathbf{1}$ forms colourless crystals which melt at room temperature. In the IR spectrum, the $\mathrm{P}-\mathrm{H}$ vibration can be observed at $2286 \mathrm{~cm}^{-1}$. Furthermore, according to the equivalent phosphorus atoms, the ${ }^{31} \mathrm{P}\left\{{ }^{1} \mathrm{H}\right\}$ NMR spectrum shows one signal at $-273.1 \mathrm{ppm}$, which is broader at room-temperature. Pyramidal inversion is a well-known phenomenon for phosphines. ${ }^{7}$ As the temperature increases to $77^{\circ} \mathrm{C}$, one sharp signal can be observed at

Fachbereich Chemie and Wissenschaftliches Zentrum für Materialwissenschaften (WZMW), Philipps-Universität Marburg, Hans-Meerwein-Straße 4, 35043 Marburg, Germany.E-mail: haenisch@chemie.uni-marburg.de; Fax: +49-6421-2825653

$\dagger$ Electronic supplementary information (ESI) available: Experimental details and crystallographic data. CCDC 966215 (2), 966216 (3) and 966217 (5). For ESI and crystallographic data in CIF or other electronic format see DOI: 10.1039/c4cc02489c
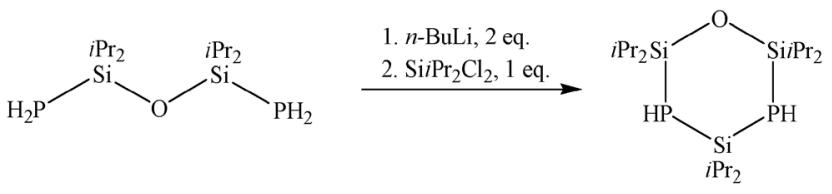

1

Scheme 1 Synthesis pathway of compound 1

-273.3 ppm (Fig. 1). At $-75^{\circ} \mathrm{C}$, the ${ }^{31} \mathrm{P}\left\{{ }^{1} \mathrm{H}\right\}$ NMR spectrum displays separate signals at -271.0 and $-278.3 \mathrm{ppm}$ which are assigned to the $r a c$ and the meso forms. The coalescence temperature amounts to $17{ }^{\circ} \mathrm{C}$, the barrier for pyramidal inversion, calculated by Eyring equation, yields $\Delta G^{\neq}=51.0 \mathrm{~kJ} \mathrm{~mol}^{-1}$.

The reaction of $\mathrm{O}\left(\mathrm{SiiPr}_{2} \mathrm{PH}\right)_{2} \mathrm{SiiPr}_{2}(\mathbf{1})$ with the hexamethyldisilazanides of strontium and barium leads to the monomeric products 2 und 3 as shown in Scheme 2. In DME, the colourless complex $\left[\mathrm{Sr}\left\{\mathrm{O}\left(\mathrm{SiiPr}_{2} \mathrm{P}\right)_{2} \mathrm{SiiPr}_{2}\right\}(\mathrm{dme})_{2}\right]$ (2) crystallizes in the orthorhombic space group $P b c a$ with eight molecules per unit cell. The dianionic $\left[\mathrm{O}\left(\mathrm{SiiPr}_{2} \mathrm{P}\right)_{2} \mathrm{SiiPr}_{2}\right]^{2-}$ entity acts as a bidentate ligand, coordinating to the strontium cation (Fig. 2). Due to saturation by two DME molecules, the strontium cation achieves the coordination number six. The siloxane group stands in one plane with both phosphorus atoms, while the silane entity has a highly distorted

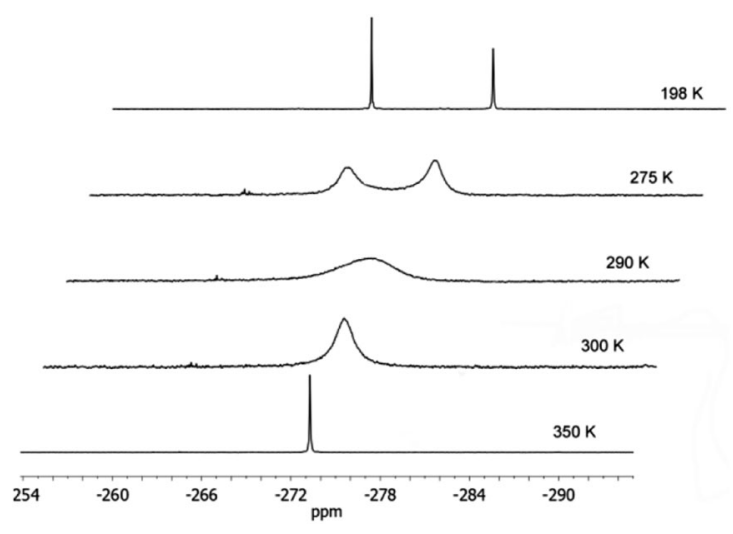

Fig. $1{ }^{31} \mathrm{P}\left\{{ }^{1} \mathrm{H}\right\}$ NMR of compound 1 . 


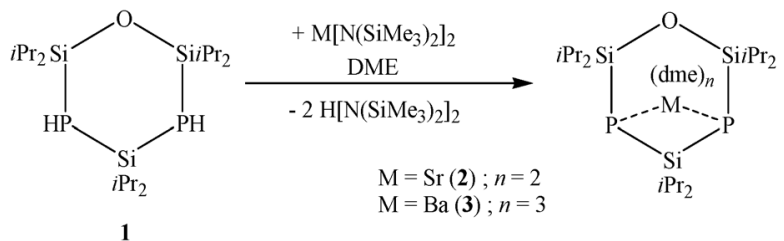

Scheme 2 Reaction of 1 with disilazanides of the heavy alkaline earth metals.

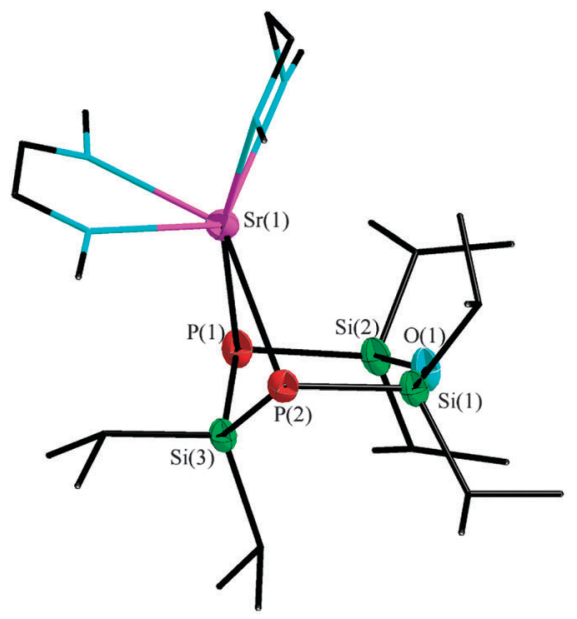

Fig. 2 Molecular structure of 2, thermal ellipsoids represent a $50 \%$ probability level, hydrogen atoms of the organic groups are not shown. Selected atom distances [pm] and angles [']: P(1)-Sr(1) 305.9(1), P(2)-Sr(1) 303.3(1), P(1)-Si(3) 224.6(1), $\mathrm{P}(2)-\mathrm{Si}(3)$ 224.5(1), $\mathrm{P}(1)-\mathrm{Si}(1)$ 220.2(1), $\mathrm{P}(1)-\mathrm{Si}(2)$ 220.8(1), Si(1)-O(1) 165.7(0), Si(2)-O(1) 165.1(1); $P(1)-S r(1)-P(2)$ 76.19(1), $P(1)-S i(3)-P(2) 113.66(2)$, Si(1)-O(1)-Si(2) 144.76(3), Si(1)-P(2)-Si(3) 96.89(2), Si(2)-P(1)-Si(3) 96.52(1).

position. Since the Si-P-Si angles amounts to $96.89(2)^{\circ}$ and $96.52(1)^{\circ}$, the ligand assumes envelope conformation.

The distances from the phosphorus atoms to the silane entity Si(3) measure 224.6(1) and 224.5(1) pm, respectively. The bond lengths from the phosphorus atoms to the siloxane group are slightly shorter, with values between 220.8(1) and 220.2(1) pm. Similar bond lengths between phosphorus and silane or siloxane groups, respectively, can also be found in other complexes with silicon functionalized phosphorus atoms. ${ }^{6}$ The ${ }^{31} \mathrm{P}\left\{{ }^{1} \mathrm{H}\right\}$ NMR spectrum shows one signal at $-266.5 \mathrm{ppm}$ with one set of ${ }^{29} \mathrm{Si}$ satellites with a coupling constant of $39.3 \mathrm{~Hz}$. A second set of satellites cannot be observed. Compound 2 is not soluble in non- or weakly polar solvents. In THF, the coordinating DME ligands of the metal cation were substituted, so we used a mixture of DME and benzene- $\mathrm{d}_{6}$ for the NMR experiments, therefore, only ${ }^{31} \mathrm{P}\left\{{ }^{1} \mathrm{H}\right\}$ NMR spectra are available.

The reaction of barium hexamethyldisilazanide with $\mathbf{1}$ leads to a monomeric structure which is similar to the strontium derivative. $\left[\mathrm{Ba}\left\{\mathrm{O}\left(\mathrm{SiiPr}_{2} \mathrm{P}\right)_{2} \mathrm{SiiPr}_{2}\right\}(\mathrm{dme})_{3}\right]$ (3) crystallizes in the orthorhombic space group $P 2_{1} 2_{1} 2_{1}$ with one additional non-coordinated DME molecule per formula unit. In contrast to compound 2 , the coordination sphere of the metal cation is completed by three DME molecules, giving a coordination number of eight (Fig. 3). ${ }^{8}$

Metalated cyclic silylphosphanides are suitable reactants for oxidative P-P bond formation by reaction with $\mathrm{C}_{2} \mathrm{H}_{4} \mathrm{Br}_{2} \cdot{ }^{9,12}$ After a few minutes already, the reaction of 3 with 1,2-dibromoethane in benzene is completed and compound 4 can be detected by

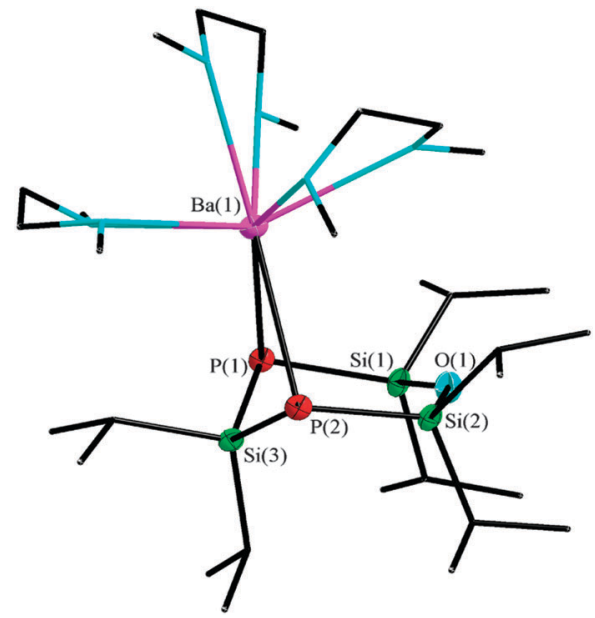

Fig. 3 Molecular structure of $\mathbf{3}$, thermal ellipsoids represent a $50 \%$ probability level, hydrogen atoms of the organic groups are not shown. Selected atom distances [pm] and angles [0]: $\mathrm{P}(2)-\mathrm{Ba}(1)$ 334.1(16), $\mathrm{P}(1)-\mathrm{Ba}(1)$ 331.3(16), $\mathrm{P}(1)-\mathrm{Si}(3)$ 223.2(20), P(2)-Si(1) 219.9(25), $\mathrm{P}(1)-\mathrm{Si}(2)$ 219.9(27), Si(1)-O(1) 165.9(27); $\mathrm{P}(1)-$ $\mathrm{Ba}(1)-\mathrm{P}(2)$ 68.38(4), $\mathrm{P}(1)-\mathrm{Si}(3)-\mathrm{P}(2)$ 113.39(8), $\mathrm{Si}(1)-\mathrm{P}(2)-\mathrm{Si}(3)$ 97.89(9), $\mathrm{Si}(1)-$ $\mathrm{O}(1)-\mathrm{Si}(2) 139.41(33)$.

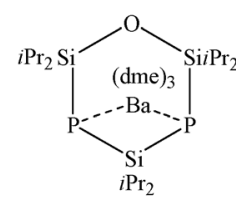

3

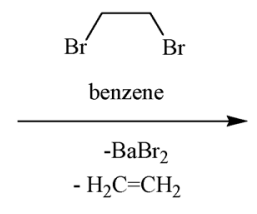

Scheme 3 Oxidation of compound 3.

NMR analysis without occurrence of any phosphorus containing by-products (Scheme 3). ${ }^{10}$ Due to P-P bond formation, 4 is a bicyclic species, containing one three-membered $\mathrm{P}_{2} \mathrm{Si}$ and one five-membered $\mathrm{OSi}_{2} \mathrm{P}_{2}$ cyclic skeleton.

In the ${ }^{31} \mathrm{P}\left\{{ }^{1} \mathrm{H}\right\}$ NMR spectrum, one observes one signal at $-311.6 \mathrm{ppm}$, relating to the equivalent phosphorus atoms. The ${ }^{29} \mathrm{Si}\left\{{ }^{1} \mathrm{H}\right\}$ NMR spectrum shows one triplet at $-20.6 \mathrm{ppm}$, belonging to the silane entity. This chemical shift is typical for three-membered $\mathrm{P}_{2} \mathrm{Si}$ heterocycles. ${ }^{5}$ Also the ${ }^{29} \mathrm{Si}\left\{{ }^{1} \mathrm{H}\right\}$ NMR signals of the siloxane entity confirm the monomeric structure of compound 4. This group appears as a multiplet at $37.1 \mathrm{ppm}$ and represents the $\mathrm{X}$ part of an $\mathrm{AA}^{\prime} \mathrm{X}$ spin system (Fig. 4). ${ }^{11}$ An iterative analysis of the signal reveals a value of ${ }^{1} J_{\mathrm{SiP}}=91 \mathrm{~Hz}$ and ${ }^{2} J_{\mathrm{SiP}}=-15 \mathrm{~Hz}$ for the silicon-phosphorus coupling and an approximate value of $50 \mathrm{~Hz}$ for the phosphorus-phosphorus coupling.

While sterically unhindered three-membered $\mathrm{P}_{2} \mathrm{Si}$ heterocycles are usually unstable and easily react to give larger ring systems, ${ }^{5}$ compound $\mathbf{4}$ is highly stable towards temperature and UV light: neither exposition to $135^{\circ} \mathrm{C}$ for a period of $18 \mathrm{~h}$ nor irradiation for $5 \mathrm{~h}$ (mercury vapour lamp) lead to any by-product. With the objective to confirm the molecular structure by X-ray analysis, we dissolved the bicyclic product 4 in toluene: after 7 days at $-25{ }^{\circ} \mathrm{C}$ single crystals were obtained. Surprisingly, a different structure than the monomeric silylphosphine $\mathbf{4}$ was discovered. 


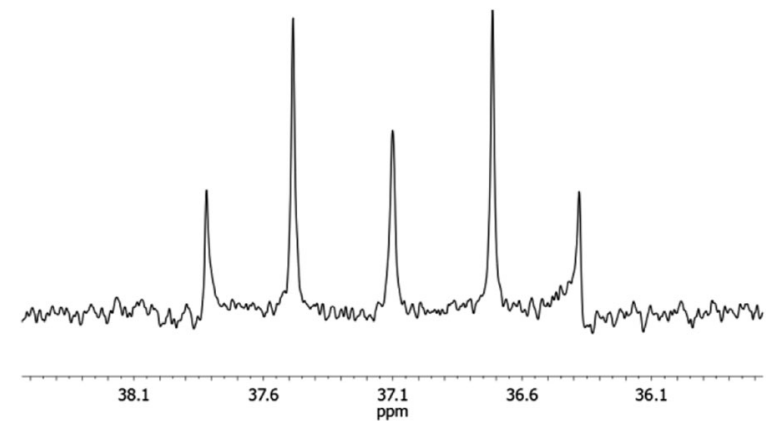

Fig. 4 Expansion of the high resolution ${ }^{29} \mathrm{Si}$ NMR spectrum of 4.

The resulting compound 5 crystallizes in the monoclinic space group $P 2_{1} / n$ in form of colourless plates. The tricyclic product 5 has an asymmetric structure and can best be described as an isopropyl substituted $\mathrm{P}_{4} \mathrm{Si}_{2}$ cycle with two exocyclic siloxane entities, building one five-membered and one six-membered heterocycle each. Compound $\mathbf{5}$ is a dimer of $\mathbf{4}$, which can easily be identified in the siloxane bridged $\mathrm{P}(4)-\mathrm{Si}(4)-\mathrm{P}(3)$ fragment (Fig. 5). Therein, the previously present P-P bond in $\mathbf{4}$ is cleaved and now connects to a second entity of $\mathbf{4}$, precisely to the silane entity $\mathrm{Si}(3)$ and the phosphorus $\mathrm{P}(2)$.

The inner $\mathrm{P}_{4} \mathrm{Si}_{2}$ cycle shows a chair conformation, while the siloxane bridges are twisted against each other: their position is nearly orthogonal. With a value of $131.90(11)^{\circ}$, the $\mathrm{Si}(1)-\mathrm{O}(1)-$ $\mathrm{Si}(2)$ angle is in the typical range of five-membered cyclic diphosphanyl-siloxanes. ${ }^{11}$ Compared to the metalated species of the six-membered cycle (compound 2 and 3 ), the $\mathrm{Si}(6)-\mathrm{O}(2)-$ $\mathrm{Si}(5)$ angle of $150.75(11)^{\circ}$ in compound 5 is more obtuse, which is due to the enlarged distance of the here non-coordinating phosphorus atoms $\mathrm{P}(3)$ and $\mathrm{P}(4)$. The silicon-phosphorus bond lengths, which vary between 228.47(10) pm for $\mathrm{P}(1)-\mathrm{Si}(3)$ and

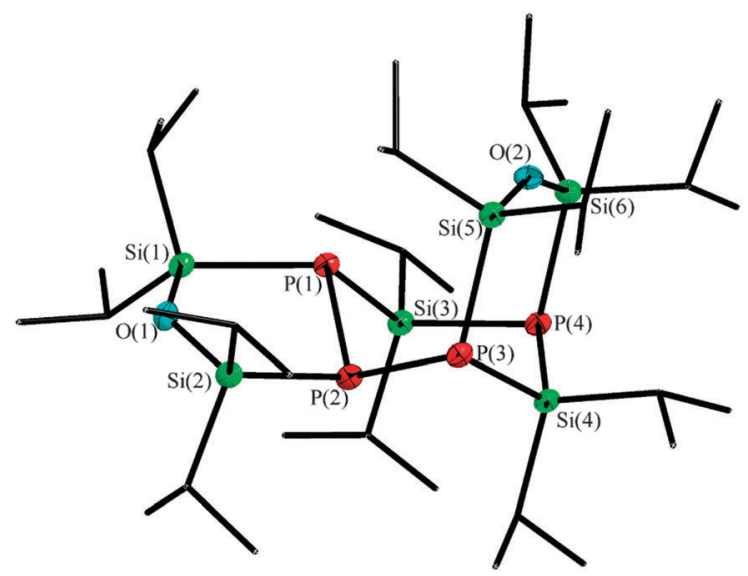

Fig. 5 Molecular structure of 5, thermal ellipsoids represent a 50\% probability level, hydrogen atoms of the organic groups are not shown. Selected atom distances [pm] and angles [']: P(1)-P(2) 220.20(8), P(2)-P(3) 220.77(10), P(1)-Si(1) 230.63(10), P(4)-Si(4) 228.47(10), P(4)-Si(6) 228.75(9), Si(1)-O(1) 165.27(16); Si(1)$\mathrm{O}(1)-\mathrm{Si}(2) 131.90(11), \mathrm{Si}(5)-\mathrm{O}(2)-\mathrm{Si}(6) 150.75(11), \mathrm{P}(1)-\mathrm{Si}(3)-\mathrm{P}(4)$ 104.69(4), P(1)$P(2)-P(3)$ 110.16(4).
230.63(10) pm for $\mathrm{Si}(1)-\mathrm{P}(1)$, accord to similar compounds. ${ }^{12}$ The ${ }^{31} \mathrm{P}\left\{{ }^{1} \mathrm{H}\right\}$ NMR spectrum shows three broad signals: $\mathrm{P}(1)$ and $\mathrm{P}(3)$ both appear at $-214.3 \mathrm{ppm}$ due to similar chemical environment, $\mathrm{P}(4)$ has a chemical shift of $-265.5 \mathrm{ppm}$ and $\mathrm{P}(2)$ can be identified at $-161.0 \mathrm{ppm}$.

We furthermore observed that the dimerization depends on the nature of the solvent, since after extensive storage at $-25{ }^{\circ} \mathrm{C}$ in DME decomposing reactions were observed instead. With the objective to comprehend the conditions of dimerization and decomposition better, we purified the monomeric product 4 by distillation in vacuo at oil bath temperatures of $200{ }^{\circ} \mathrm{C}$ (b.p. $96^{\circ} \mathrm{C}, 1 \times 10^{-3} \mathrm{mbar}$ ). After purification, the previous oily compound 4 is a white solid with a melting point of $83{ }^{\circ} \mathrm{C}$. Interestingly, under consistent conditions as used before, neither dimerization nor decomposition of the pure diphosphasilirane $\mathbf{4}$ was observed. This led us to the conclusion that impurities like remaining metal bromides induce dimerization and decomposition, depending on the solvent used.

To sum up, cyclic silylphosphanes which contain two P-H units are valuable precursors for the synthesis of stable diphosphasiliranes. The bicyclic compound 4 presented here shows high stability towards temperature and UV light and can therefore be isolated via distillation. The subsequently observed oligomerization at low temperatures is promoted by impurities, since rearrangement is not observed for the purified compound 4 .

The authors thank Dr E. Matern (Institut für Anorg. Chemie, KIT) for his valuable help with the NMR experiments and simulations. This work was financially supported by the Deutsche Forschungsgemeinschaft (DFG).

\section{Notes and references}

1 (a) W. W. Schoeller and T. Dabisch, J. Chem. Soc., Chem. Commun., 1985, 23, 1706; (b) W. W. Schoeller, V. Staemmler, P. Rademacher and E. Niecke, Inorg. Chem., 1986, 25, 4382; (c) M. Weidenbruch, Chem. Rev., 1995, 95, 1479; (d) M. Driess and H. Grützmacher, Angew. Chem., Int. Ed. Engl., 1996, 35, 828.

2 A. G. Baboul and H. B. Schlegel, J. Am. Chem. Soc., 1996, 118, 8444.

3 M. Baudler, J. Hahn, H. Dietsch and G. Fürstenberg, Z. Naturforsch., B, 1976, 31, 1305.

4 M. Driess, H. Pritzkow, S. Rell and R. Janoschek, Inorg. Chem., 1997, 36, 5212.

5 (a) M. Baudler and H. Jongebloed, Z. Anorg. Allg. Chem., 1979, 458, 9; M. Baudler, Angew. Chem., 1982, 94, 520; (b) M. Baudler, Angew. Chem., Int. Ed. Engl., 1982, 21, 492.

6 (a) C. v. Hänisch and P. Kopecky, Z. Anorg. Allg. Chem., 2010, 636, 1522; (b) P. Kopecky, C. v. Hänisch, F. Weigend and A. Kracke, Eur. J. Inorg. Chem., 2010, 258; (c) S. Traut, C. v. Hänisch and H.-J. Kathagen, Eur. J. Inorg. Chem., 2009, 777; (d) C. von Hänisch and S. Stahl, Angew. Chem., 2006, 118, 2360.

7 (a) G. Hoge, J. Am. Chem. Soc., 2004, 126, 9921; (b) O. J. Scherer and R. Mergner, J. Organomet. Chem., 1972, 40, 64.

8 Also the calcium congener $\left[\mathrm{Ca}\left\{\mathrm{O}\left(\mathrm{SiiPr}_{2} \mathrm{P}\right)_{2} \mathrm{SiiPr}_{2}\right\}(\mathrm{dme})_{2}\right]$ was obtained by analogous reaction of $\mathrm{O}\left(\mathrm{SiiPr}_{2} \mathrm{PH}\right)_{2} \mathrm{SiiPr}_{2}$ (1) with calcium silazanide. Since the reaction showed only small yield, beside crystal structure determination no further analysis was possible.

9 V. Cappello, J. Baumgartner, A. Dransfels and K. Hassler, Eur. J. Inorg. Chem., 2006, 4589.

10 With 1,2-dibromoethane the strontium derivative 2 reacts in an analogous manner as compound 3.

11 R. Radeglia, J. Prakt. Chem., 1989, 331, 863.

12 A. Kracke and C. v. Hänisch, Eur. J. Inorg. Chem., 2011, 3374. 